\title{
Anxiety, depression and health-related quality of life in those injured by landmines, Ilam, Islamic Republic of Iran
}

R. Asadollahi, ${ }^{1}$ M. Saghafinia, ${ }^{2}$ N. Nafissi, ${ }^{3}$ A. Montazeri, ${ }^{4}$ M. Asadollahi ${ }^{5}$ and M. Khatami ${ }^{6}$

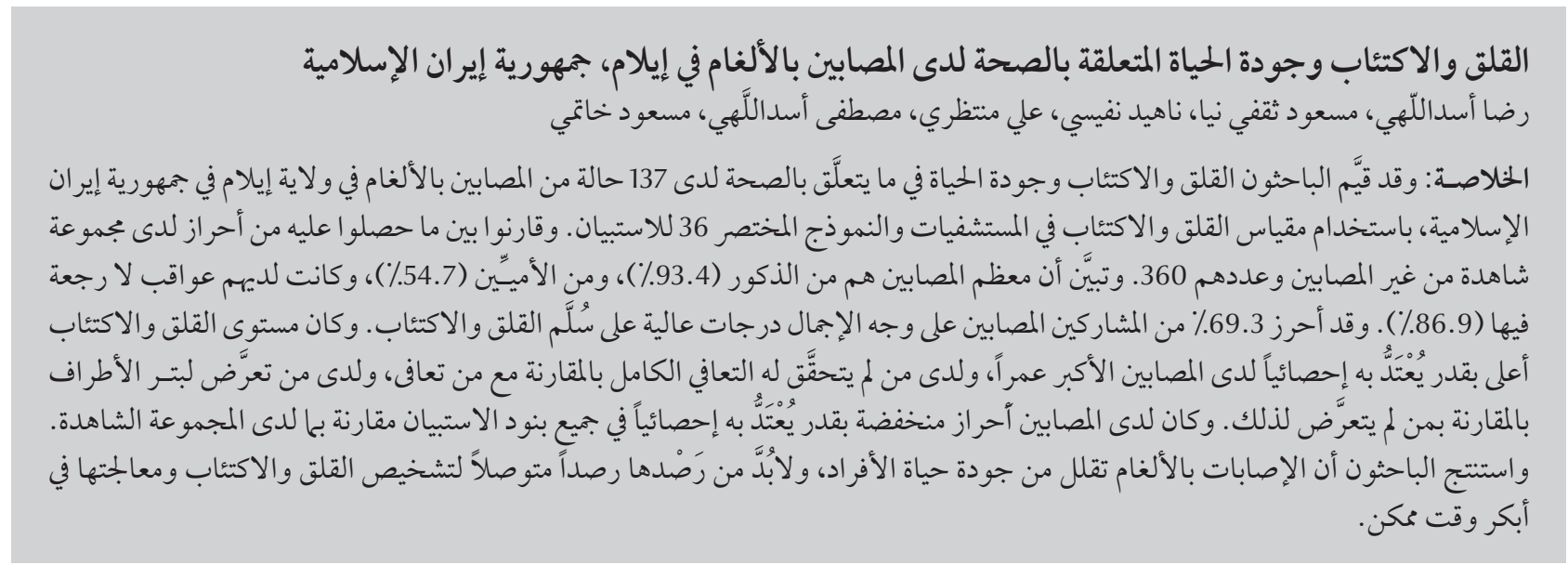

ABSTRACT We assessed depression, anxiety and health-related quality of life (HRQOL) in 137 cases of landmine injury in Ilam province, using the Hospital Anxiety \& Depression Scale (HADS) and the Short Form Health Survey (SF36) questionnaires. We also compared their scores with an uninjured control group $(n=360)$. Most of the injured were male (93.4\%) and illiterate (54.7\%) with some irreversible sequelae (86.9\%). Overall, $69.3 \%$ of the injured participants scored high for both anxiety and depression. The level of anxiety and depression was significantly higher in older cases, those not completely recovered compared with recovered cases and those with amputation compared with those without amputation. The injured also had significantly lower mean scores in all HRQOL components than the control group. Landmine injured should be monitored for early identification and treatment of depression and anxiety.

Anxiété, dépression, et qualité de vie liée à la santé chez les personnes blessées par des mines terrestres, Ilam, République islamique d'Iran

RÉSUMÉ Nous avons évalué la dépression, I'anxiété, la qualité de vie liée à la santé (QVLS) dans 137 cas de dommages corporels par les mines terrestres dans la province d'Ilam, en utilisant l'échelle HAD (Hospital Anxiety \& Depression) et les questionnaires du Short Form Health Survey (SF36). Nous avons également comparé leurs scores avec un groupe témoin non blessé $(\mathrm{n}=360)$. La plupart des personnes blessées étaient de sexe masculin (93,4\%) et illettrées (54,7\%) et présentaient des séquelles irréversibles (86,9\%). Globalement, 69,3\% des participants blessés présentaient des scores élevés pour l'anxiété et la dépression. Le niveau d'anxiété et de dépression était nettement supérieur dans les cas plus anciens, chez ceux qui n'étaient pas totalement rétablis par rapport à ceux qui l'étaient et ceux qui avaient été amputés par rapport à ceux qui ne l'avaient pas été. De même, les personnes blessées avaient des scores moyens pour toutes les composantes de la QVLS nettement inférieurs à ceux du groupe témoin. Les dommages corporels par les mines terrestres doivent être surveillés pour identifier et traiter rapidement la dépression et l'anxiété. 


\section{Introduction}

The widespread use of landmines in military conflicts around the world and their continuing legacy for the civilian population in injuries, amputations, disabilities and economic costs is recognized as a major problem. Around 70 countries are contaminated with almost 60-70 million landmines [1], which cause almost 800 deaths and 1200 injuries each month $[2,3]$. Children are more likely to die from landmine injuries than adults [4].

Governments have responded to the humanitarian crisis caused by landmines and explosive remnants of war in different ways, such as banning antipersonnel mines in the 1997 Ottawa Convention and assigning the responsibilities for removing explosive remnants of war [5]. In an effort to prevent and address the human suffering caused by landmines, more than 750 nongovernmental organizations in 44 countries have joined together to form the International Campaign to Ban Landmines (ICBL) [6]. Enough investment for minesweeping soon after a war and public education for taking precaution against accidents are the other measures to prevent landmine injuries.

The Islamic Republic of Iran is one of the mostlandmine-contaminated countries in the world. During the 8-year war with Iraq (1980-88), vast areas of the Islamic Republic of Iran were polluted with landmines. These areas are mostly sited in the western and south-western provinces of Kerman Shah, Kurdistan, Ilam, West Azerbaijan and Khuzestan. Up to 16 million landmines and other unexploded ordnances (UXOs) cover a surface area of about 4000 hectares of these 5 provinces [7]. Grazing livestock, farming and mine-detecting are the most common activities which lead to mine explosions in these areas [8].

People who survive a mine explosion sustain some irreversible consequences, such as amputations, burns and blindness, and they may lose their role in their family, community, society and economic state. Therefore, they are highly prone to experience psychological disorders. Social stigmatization, rejection and unemployment are common psychosocial risks they face [9].

Post-traumatic stress disorder, acute stress reaction, anxiety disorder and depression have been found to be very significantly higher in those injured by landmines than in the general population. There are also remarkable changes in the areas offunctional ability, religious practice, use of alcohol and social relationships $[10,11]$. Landmine injury has been found as one of the psychosocial risk factors for poorer mental health and social functioning outcomes [12].

Landmine victims' psychological recovery is greatly influenced by the individual's resilience characteristics, social support, medical care, economic situation and societal attitudes toward them [13].

Ilam, in the west of the Islamic Republic of Iran, is the province with the second greatest landmine pollution in the country. Because of the seriousness of psychological disorders among mine victims and the few previous studies available, we aimed to assess the symptoms, severity and prevalence of anxiety and depression disorders among mine victims in this province, and to evaluate their quality of life taking different parameters into account. Measuring the quality of life, when the resources are limited, can be helpful to assign priorities for health planning and estimate the burden of diseases.

\section{Methods}

This was a cross-sectional study conducted at Ilam during 2007-2008. Landmine victims were from different landmine-infested areas of Ilam such as Mehran, Dehloran, Chalab, Changooleh and Salehabad.

The records of those injured by landmines registered in Ilam provincial governors' register $(n=160)$ were selected by simple random sampling. Each registered person has a unit number. Unit numbers were selected according to a table of random numbers. After locating the injured through their addresses (147 out of 160), the purpose and the methods of the study were explained and informed consent obtained from the individuals. Demographic information including age, sex, marital status, education level, type of injury, possible disability, length of time since the injury, recovery status and past medical history were asked in a face to face interview. Then, 36 questions of the Persian Short Form 36 (SF36) questionnaire for evaluation of the healthrelated quality of life (HRQOL) [14] and 14 questions of Persian Hospital Anxiety \& Depression Scale (HADS) [15] were completed by the participants under supervision of a trained nurse. If the respondent was illiterate, the questionnaire was read to him/her by an interviewer. By using a face to face interview, there were few missing data and the problem of illiterate individuals was not encountered. To eliminate any selection bias, patients with specific life events during the preceding 6 months, such as bereavement, psychotic illness or substance abuse and another concurrent active chronicillness, were excluded $(n=10)$.

Agroup of non-injured controls $(n=$ 360) also completed the SF36 questionnaire. They were drawn from individuals referred to Ilam medical clinics for family planning or for other non-curative purposes. They were selected randomly from different clinics. They did not have any significant past history of chronic medical or psychological illness. Subjects and controls were matched on age and sex so there were not significant differences between them with respect to these two variables.

\section{HADS}

The questionnaire from the Persian adapted version of the HADS was used; 
it has been shown to be both valid and reliable [15]. HADS is a rapid selfreport questionnaire which measures depression and generalized anxiety. The term Hospital in its title suggests that it is only valid in such a setting but many studies conducted throughout the world have confirmed that it is valid when used in community settings and primary care medical practice [16]. HADS comprises statements that the patient rates based on their experience over the past week. The 14 statements are relevant to generalized anxiety (7 statements) or depression (again 7), the latter being largely (but not entirely) composed of reflections of the state of anhedonia. Each question has 4 possible responses, which are scored on a scale of 3 to 0 . HADS is divided into 3 [normal $(0-7)$, borderline $(8-11)$, caseness $(11-21)]$ or 4 [normal $(0-7)$, mild (8-10), moderate (11-15) and sever (16-21)] ranges. The maximum score is therefore 21 for depression and 21 for anxiety [17].

\section{SF36}

The questionnaire from the Persian adapted version ofSF36, which has been shown to be both valid and reliable, was used [14]. This questionnaire is a multipurpose, short-form health survey with only 36 questions. It yields an 8-scale profile of scores: physical functioning (PF), 10 items; role physical (RP), 4 items; bodily pain (BP), 2 items; general health (GH), 5 items; vitality (VT), 4 items; social functioning (SF), 2 items; role emotional (RE), 3 items; and mental health (MH), 5 items. Each item has response categories describing the level of functioning of the patient from normal to severely impaired. All but one of the 36 items (self-reported health transition) is used to score the $8 \mathrm{SF}$ 36 scales. Each item is used in scoring only one scale. The SF-36 subscales are standardized to a $0-100$ point scale, and higher scores represent better quality of life $[18,19]$.
SF-36 is a generic measure, as opposed to one that targets a specific age, disease, or treatment group. Studies demonstrate that the SF-36 is very usefulfor documenting differences between sick and well people in order to evaluate a wide range of different treatments and for estimating the relative burden of different medical conditions $[19,20]$.

\section{Statistical analysis}

HADS analysis: The one-way analysis of variance (ANOVA) and independent samples $t$-test were performed to compare anxiety and depression with regard to the sociodemographic characteristics of the injured. In addition, logistic regression analysis was carried out to examine which factors show the strongest association with anxiety and depression. For the purpose of the analysis relative to the recommended cut-off points, patients were divided into 2 groups: those who scored 0 to 7 as normal and those who scored 8 and above as probable cases.

SF-36 analysis: Results were expressed as frequencies, means and standard deviations (SDs). SF-36 subscale scores for the participants in this study were compared across the 2 groups of study using nonparametric tests. Two independent sample test (MannWhitney U test) and the chi-squared test were also used to explore the impact of the sociodemographic factors on the HRQOL among the injured.

Bivariate Pearson and Spearman correlations were used to determine any correlation between anxiety and depression.

Data were analysed with SPSS, version 16.

\section{Results}

\section{Characteristics of the landmine victims}

Of the total number of the injured (160) selected randomly, 147 people were found and 137 were included in the study (85.6\%). Their mean age was 38.1 (SD 12.8) years; most of the injured were male (93.4\%), married (75.2\%) and illiterate (54.7\%). Of the 137 participants, 58 (42.3\%) had at least one type of amputation and $86.9 \%$ of cases had sustained irreversible consequences, such as amputations and burns. They were considered as not completely recovered cases. The mean length of time since the injury (time of explosion) was 12.7 (SD 7.6) years. The demographic characteristics of the injured are shown in Table 1.

\section{Anxiety and depression}

On the basis of the results of HADS, 95 of the 137 injured (69.3\%) scored high (caseness $\geq 11$ ) for both anxiety and depression (77.4\% for anxiety and $79.6 \%$ for depression) and 5.8\% were within the normal range $(0-7)$ for both $(10.2 \%$ for anxiety and $8 \%$ for depression). The mean anxiety score was 13.0 (SD 3.9) and for depression this was 13.2 (SD 3.9). Anxiety and depression correlated significantly $(r=$ $0.7, P<0.01)$.

\section{Anxiety level}

Of the participants, 14 people had a normal score, 17 were borderline and 106 were categorized as cases of anxiety.

The level of anxiety was significantly lower in participants who were considered to have recovered from their injury (mean score of 10.4) compared with those without complete recovery (mean score of 13.4) $(P=0.002)$.

There was no significant association of age, gender, marital status, educational level and presence of amputation with the anxiety level.

\section{Depression level}

Of the participants, 11 had a normal score, 17 were borderline and 109 were categorized as cases of depression.

The level of depression was significantly lower in participants considered to have recovered from their injury (mean score of 9.5) compared with 
those without complete recovery (mean score of 13.7) $(P<0.0001)$.

No significant differences were found between demographic features and depression.

On regression analysis, both anxiety and depression showed the strongest association with recovery status [odds ratio (OR) for anxiety $=0.21,95 \%$ confidence interval (CI): 0.06-0.73, $P=0.01]$; OR for depression $=0.13$, 95\% CI: 0.03-0.51, $P=0.003$. No other variables showed statistically significant association.

\section{Quality of life (SF36)}

For evaluation of the injured mean scores in SF 36 subscales, we used age- and sex-matched controls from the same geographical area. Comparison of their age, gender and educational level are presented in Table 1.

The mean scores measured for each of the SF 36 subscales for both the landmine victims and the controls are listed in Table 2. The minimum score for the injured was 18.7 (SD 21.0) for RP subscale (role limitations due to physical problems) and the maximum score was 37.4 (SD 27.4) for SF.

Table 2 shows that those injured by landmines had significantly worse mean scores in all HRQOL dimensions when compared with data from the control group. The most striking differences were observed in the BP subscale (22.6 vs 67.3) and PF (34.6 vs 78.8 ). The smallest differences, although still statistically significant, were for VT (30.3 vs 60.7) and SF (37.4 vs 67.9). The overall test statistic was statistically significant $(P<0.0001)$ for the 8 subscales indicating that there was a relationship between group membership and HRQOL.

We examined the association between the demographic characteristics of the injured and the scores measured for the 8 subscales (Tables 3-6). The Older injured had significantly lower scores in all measures as expected

\begin{tabular}{|c|c|c|}
\hline \multirow[t]{2}{*}{ Variable } & Cases $(n=137)$ & Controls $(n=360)$ \\
\hline & No. (\%) & No. (\%) \\
\hline \multicolumn{3}{|l|}{ Sex } \\
\hline Male & $128(93.4)$ & $284(78.9)$ \\
\hline Female & $9(6.6)$ & $76(21.1)$ \\
\hline \multicolumn{3}{|l|}{ Marital status } \\
\hline Single & $34(24.8)$ & NA \\
\hline Married & $103(75.2)$ & NA \\
\hline \multicolumn{3}{|l|}{ Educational level } \\
\hline Illiterate & $75(54.7)$ & $167(46.4)$ \\
\hline Primary to intermediate & $37(27)$ & $83(23.0)$ \\
\hline High school & $18(13.1)$ & $72(20.0)$ \\
\hline Above high school & $7(5.1)$ & $38(10.6)$ \\
\hline \multicolumn{3}{|l|}{ Recovery status } \\
\hline Recovered from injury & $18(13.1)$ & - \\
\hline Not completely recovered & $119(86.9)$ & - \\
\hline \multicolumn{3}{|l|}{ Amputation } \\
\hline Yes & $58(42.3)$ & - \\
\hline No & $79(57.7)$ & - \\
\hline \multicolumn{3}{|l|}{ Age (years) } \\
\hline Mean (SD) & $38.1(12.8)$ & $33.6(15)$ \\
\hline Range & $8-75$ & $13-77$ \\
\hline \multicolumn{3}{|c|}{ Length of time since accident (years) } \\
\hline Mean (SD) & $12.7(7.6)$ & - \\
\hline Range & $0.5-30$ & - \\
\hline
\end{tabular}

$N A=$ not available $S D=$ standard deviation .

\begin{tabular}{llccc}
\hline $\begin{array}{l}\text { Table 2 Comparison of SF-36 subscales between the landmine injured and control } \\
\text { groups }\end{array}$ & Group & Mean & SD & P-value $^{\text {a }}$ \\
\hline SF-36 subscale & Injured & 34.6 & 27.4 & $<0.0001$ \\
Physical functioning (PF) & Controls & 78.8 & 23.0 & \\
Role physical (RP) & Injured & 18.7 & 21.0 & $<0.0001$ \\
& Controls & 52.9 & 34.3 & \\
Bodily pain (BP) & Injured & 22.6 & 26.0 & $<0.0001$ \\
& Controls & 67.3 & 22.3 & \\
General health (GH) & Injured & 24.6 & 20.7 & $<0.0001$ \\
& Controls & 60.0 & 20.2 & \\
Vitality (VT) & Injured & 30.3 & 18.5 & $<0.0001$ \\
& Controls & 60.7 & 19.7 & \\
Social functioning (SF) & Injured & 37.4 & 26.4 & $<0.0001$ \\
& Controls & 67.9 & 23.4 & \\
Role emotional (RE) & Injured & 20.7 & 22.6 & $<0.0001$ \\
& Controls & 52.6 & 35.8 & \\
Mental health (MH) & Injured & 32.5 & 20.7 & $<0.0001$ \\
& Controls & 63.8 & 18.6 & \\
\hline
\end{tabular}

aMann-Whitney $U$ test.

$S D=$ standard deviation 


\begin{tabular}{|c|c|c|c|c|c|c|}
\hline \multirow[t]{3}{*}{ SF-36 subscale } & \multicolumn{5}{|c|}{ Age group (years) } & \multirow[t]{3}{*}{$P$-value ${ }^{\mathrm{a}}$} \\
\hline & $15-24$ & $25-34$ & $35-44$ & $45-54$ & $\geq 55$ & \\
\hline & Mean (SD) & Mean (SD) & Mean (SD) & Mean (SD) & Mean (SD) & \\
\hline Physical functioning (PF) & $40.0(33.9)$ & $40.0(28.2)$ & $33.4(24.2)$ & $27.7(25.7)$ & $24.0(24.4)$ & $<0.0001$ \\
\hline Role physical (RP) & $27.9(27.7)$ & $23.2(20.4)$ & $16.4(23.4)$ & $13.3(12.9)$ & $11.4(12.7)$ & $<0.0001$ \\
\hline Bodily pain (BP) & $36.8(29.5)$ & $28.0(29.3)$ & $20.5(24.8)$ & $14.8(16.5)$ & $11.5(17.6)$ & $<0.0001$ \\
\hline General health $(\mathrm{GH})$ & $37.2(30.1)$ & $23.2(21.2)$ & $26.1(18.0)$ & $19.8(14.8)$ & $18.7(15.7)$ & $<0.0001$ \\
\hline Vitality (VT) & $41.2(21.8)$ & $30.3(19.5)$ & $30.0(17.1)$ & $30.6(15.4)$ & $22.9(15.9)$ & $<0.0001$ \\
\hline Social functioning (SF) & $41.1(27.5)$ & $39.9(27.5)$ & $37.8(26.7)$ & $34.8(24.9)$ & $29.1(25.2)$ & $<0.0001$ \\
\hline Role emotional (RE) & $29.4(26.0)$ & $29.2(21.3)$ & $14.0(21.4)$ & $17.7(24.7)$ & $12.5(16.4)$ & $<0.0001$ \\
\hline Mental health $(\mathrm{MH})$ & $45.1(25.3)$ & $31.2(21.9)$ & $34.8(17.2)$ & $26.1(19.7)$ & $25.8(15.6)$ & $<0.0001$ \\
\hline
\end{tabular}

${ }^{a}$ Chi-squared test.

$S D=$ standard deviation

(Table 3). There were only a few female injured in our study $(n=9)$ and gender was not related to any of the subscales. Marital status was significantly related to BP subscale $(P=0.004)$ as the injured who were single had a higher mean score than married injured (32.7 vs 19.3). All scales except RP and RE had significantly higher mean scores in recovered cases against not completely recovered cases (Table 4). As expected, PF, RP and $\mathrm{BP}$ were considerably lower in the injured with any type of amputation compared to those without amputation (Table 5). The level of education was also related to all of the scales; those with a higher level of education had higher mean scores, i.e. better HRQOL (Table 6).

\section{Discussion}

We found that those injured by landmines experience high scores for both anxiety and depression. Furthermore, anxiety and depression were correlated, i.e. patients with high scores for anxiety had high scores for depression too. Landmine accidents not only cause physical impairments in the survivors, but also psychological trauma, such as post-traumatic stress disorder, depression and anxiety, all of which may affect their quality of life. Denial of new body image, indeterminate future and loss of confidence may increase continuous anxiety and depression [21].

Sinici et al. showed high anxiety levels in more than $90 \%$ of landmineinjured patients in Turkey who had posttraumatic stress disorder [10]. In Sri
Lanka, Gunaratnam et al. also reported a high percentage of mine victims with anxiety disorder and depression [11]. A population-based mental health survey by the Center for Disease Control and Prevention in Afghanistan found that landmine injuries (in non-disabled respondents) were associated with a higher prevalence of anxiety symptoms [22].

Personal factors such as intelligence, socioeconomic level, gender, age, level of education, past experiences and environmental elements, such as type of trauma, intensity, treatment and rehabilitation after trauma, may determine the level of anxiety and depression [23]. In our study, the level of anxiety and depression was significantly lower in participants with recovered in-

\begin{tabular}{|c|c|c|c|}
\hline SF-36 subscale & $\begin{array}{l}\text { Recovered } \\
\text { Mean (SD) }\end{array}$ & $\begin{array}{c}\text { Not completely recovered } \\
\text { Mean (SD) }\end{array}$ & $P$-value ${ }^{\text {a }}$ \\
\hline Physical functioning (PF) & $52.5(30.2)$ & $31.8(26.0)$ & 0.006 \\
\hline Role physical (RP) & $27.7(31.9)$ & $17.3(18.7)$ & 0.3 \\
\hline Bodily pain (BP) & $44.1(34.7)$ & $19.3(22.9)$ & 0.005 \\
\hline General health $(\mathrm{GH})$ & $41.7(22.5)$ & $22.0(19.1)$ & $<0.0001$ \\
\hline Vitality (VT) & $43.8(21.6)$ & $28.2(17.2)$ & 0.004 \\
\hline Social functioning (SF) & $55.5(21.5)$ & $34.6(26.1)$ & 0.001 \\
\hline Role emotional (RE) & $25.9(29.2)$ & $19.9(21.4)$ & 0.5 \\
\hline Mental health $(\mathrm{MH})$ & $50.6(23.7)$ & $29.7(18.8)$ & $<0.0001$ \\
\hline
\end{tabular}

aMann-Whitney U test.

$S D=$ standard deviation. 


\begin{tabular}{|c|c|c|c|}
\hline SF-36 subscale & $\begin{array}{c}\text { Amputated (any type) } \\
\text { Mean (SD) }\end{array}$ & $\begin{array}{l}\text { Without any amputation } \\
\text { Mean (SD) }\end{array}$ & $P$-value ${ }^{a}$ \\
\hline Physical functioning (PF) & $29.0(25.5)$ & $38.8(28.2)$ & 0.03 \\
\hline Role physical (RP) & $12.9(16.3)$ & $23.0(23.2)$ & 0.008 \\
\hline Bodily pain (BP) & $17.7(23.7)$ & $26.3(27.2)$ & 0.03 \\
\hline General health $(\mathrm{GH})$ & $23.6(21.4)$ & $25.4(20.2)$ & 0.4 \\
\hline Vitality (VT) & $29.3(17.5)$ & $31.1(19.4)$ & 0.7 \\
\hline Social functioning (SF) & $35.3(28.4)$ & $38.9(24.9)$ & 0.3 \\
\hline Role emotional (RE) & $19.5(22.5)$ & $21.6(22.7)$ & 0.5 \\
\hline Mental health $(\mathrm{MH})$ & $31.6(19.2)$ & $33.1(21.8)$ & 0.9 \\
\hline
\end{tabular}

${ }^{a}$ Mann-Whitney $U$ test.

$S D=$ standard deviation

jury in comparison with those without complete recovery.

Assessing the health-related quality of life, it seems that patients with landmine injuries experience a lower quality of life as compared to the general population. Age, educational level, marital status, recovery status and presence of amputation may affect different aspects of quality of life. Landmine accident victims with high levels of anxiety and subsequent negative feelings may not feel that they are as positive as before. In a survey of mental health outcomes and social functioning of refugees living in Thai-Burmese border camps, landmine injury was found as one of the psychosocial risk factors for poorer mental health and social functioning outcomes [12].

Poor quality of life has been stated in different veterans of the Iran-Iraq war. For instance, $85 \%$ of patients affected by mustard gas in Sardasht, Islamic Republic of Iran, had lower quality of life and physical health was the major cause [24]. A study of the quality of life in Iranian females with spinal cord injury that occurred during the Iran-Iraq war or post-war landmine accidents demonstrated significantly lower mean scores in all subscales of SF36 compared to the normal population [25]. The same results have been seen in the veterans of other wars like the 1990-91 Persian GulfWar; veterans experienced poorer health on most subjective outcomes than non-deployed military personnel [26]. Likewise, functional health status was significantly lower in the Persian Gulf War veterans compared with published United States population norms for each of the SF36 subscales [27].

Dougherty determined that transtibial amputees from the Vietnam
War (65\% of the injuries were due to tripping a landmine or booby trap) led relatively normal lives after sustaining the amputation. However, addition of another major injury had significant long-term consequences with regard to SF-36 scores and resulted in a need for psychological care [28].

Our study shows people injured by landmines are at risk of psychological ill health. Thus such injured individuals need close observation to determine and treat increased anxiety and depression which worsens the quality of life. Special attention should be paid to appropriate psychological rehabilitation throughout their treatment plan.

As in this study only a part of those injured by landmines registered in Ilam were evaluated, additional studies are needed to include participants of all landmine polluted geographical areas

\begin{tabular}{lccccc}
\hline \multicolumn{7}{l}{ Table 6 Comparison of the SF-36 scores for the landmine injured by educational level } & & \\
\hline SF-36 subscale & Illiterate & Primary/Intermediate & High school & Above high school & $\boldsymbol{P}_{\text {-value }}$ \\
& Mean (SD) & Mean (SD) & Mean (SD) & Mean (SD) & \\
Physical functioning (PF) & $28.4(24.5)$ & $37.4(27.8)$ & $45.2(31.6)$ & $57.1(24.8)$ & $<0.0001$ \\
Role physical (RP) & $15.7(15.8)$ & $19.5(22.1)$ & $25.0(28.8)$ & $26.3(31.4)$ & $<0.0001$ \\
Bodily pain (BP) & $13.9(18.4)$ & $30.7(29.2)$ & $34.4(20.3)$ & $36.4(35.0)$ & $<0.0001$ \\
General health (GH) & $19.3(14.6)$ & $28.0(24.5)$ & $33.8(17.6)$ & $35.7(27.7)$ & $<0.0001$ \\
Vitality (VT) & $26.2(15.6)$ & $31.7(20.3)$ & $35.7(19.0)$ & $41.9(21.2)$ & $<0.0001$ \\
Social functioning (SF) & $37.1(25.4)$ & $32.7(27.2)$ & $44.6(24.8)$ & $45.1(29.4)$ & $<0.0001$ \\
Role emotional (RE) & $14.8(23.4)$ & $20.7(22.7)$ & $21.9(22.3)$ & $23.8(25.1)$ & $<0.0001$ \\
Mental health (MH) & $28.3(17.0)$ & $31.3(22.7)$ & $40.5(24.1)$ & $48.6(21.8)$ & $<0.0001$ \\
\hline
\end{tabular}

${ }^{a}$ Chi-squared test.

$S D=$ standard deviation . 
to obtain comprehensive data. Based on comprehensive results, national programmes should be set up for early identification and subsequent referral for treatment of depression and anxiety. This may decrease the likelihood of these conditions affecting long-term quality of life so negatively.

\section{Acknowledgements}

We acknowledge the invaluable contribution by Mr Kamran Baloochi, head nurse of Ilam University Hospital, for his help in accessing the data. The authors would like to acknowledge the financial support provided by Iran
Helal Institute of Applied Science \& Technology, Tehran. The staff of Ilam provincial governor and the Iranian Institute for Health Sciences Research, Tehran are highly appreciated for their valuable cooperation. We also thank all the injured for participating in the study.

\section{References}

1. Centers for Disease Control and Prevention (CDC). Injuries associated with landmines and unexploded ordnance--Afghanistan, 1997-2002. MMWR Morbidity and Mortality Weekly Report, 2003, 52, 859-862.

2. Office of International Security and Peacekeeping Operations. Hidden killers: the global landmine crisis. Washington DC, US Department of State, Bureau of Political-Military Affairs, 1994.

3. International Committee of the Red Cross. Anti personnel mines: an overview 1996. Geneva, International Committee of the Red Cross, 1996.

4. Coupland RM, Korver A. Injuries from antipersonnel mines: the experience of the International Committee of the Red Cross. BMJ (Clinical Research Edition), 1991, 303:1509-1512.

5. International Committee of the Red Cross. Anti-personnel landmines and explosive remnants of war (http://www.icrc. org/eng/mines, accessed 7 September 2010).

6. Winslow PC. The case against landmines (http://www.redcross.int/EN/mag/magazine1997_2/10-11.html, accessed 7 September 2010).

7. Soroush AR et al. Amputations due to landmine and unexploded ordnances in post-war, Iran. Archives of Iranian Medicine, 2008, 11:595-597.

8. Soroush AR et al. [The human costs of landmine and UXOs, 1st ed]. Tehran, Janbazan Medical and Engineering Research Center (JMERC), 2007 [In Farsi].

9. Somasundaram DJ, Renol KK. The psychosocial effects of landmines in Cambodia. Medicine, Conflict, and Survival, 1998, 14:219-236

10. Sinici $\mathrm{E}$ et al. [The assessment of anxiety levels in patients with posttraumatic stress disorder]. Acta Orthopaedica et Traumatologica Turcica, 2004, 38:145-148 [In Turkish].

11. Gunaratnam HR, Gunaratnam S, Somasundaram D. The psychosocial effects of landmines in Jaffna. Medicine, Conflict, and Survival, 2003, 19:223-334.

12. Lopes Cardozo B et al. Karenni refugees living in Thai-Burmese border camps: traumatic experiences, mental health outcomes, and social functioning. Social Science \& Medicine, 2004, 58:2637-44.

13. Ferguson AD, Richie BS, Gomez MJ. Psychological factors after traumatic amputation in landmine survivors: the bridge between physical healing and full recovery. Disability and Rehabilitation, 2004, 26:931-8.
14. Montazeri A et al. The Short Form Health Survey (SF-36): translation and validation study of the Iranian version. Quality of Life Research, 2005, 14:875-882

15. Montazeri A et al. The Hospital Anxiety and Depression Scale (HADS): translation and validation study of the Iranian version. Health and Quality of Life Outcomes, 2003, 1:14 (http://www. hqlo.com/content/1/1/14, accessed 7 September 2010).

16. Bjelland I et al. The validity of the Hospital Anxiety \& Depression Scale; an updated review. Journal of Psychosomatic Research, 2002, 52:69-77.

17. Zigmond AS, Snaith RP. The hospital anxiety and depression scale. Acta Psychiatrica Scandinavica, 1983, 67:361-370.

18. Ware JE et al. Sf-36 health survey, manual \& interpretation guide. Boston, The Health Institute, New England Medical Center, 1997.

19. Ware JE Jr, Sherbourne CD. The MOS 36-Item Short-Form Health Survey (SF-36). I. Conceptual framework and item selection. Medical Care, 1992, 30:473-483.

20. Aaronson NK et al. International Quality of Life Assessment (IQOLA) Project. Quality of Life Research, 1992, 1:349-351.

21. Herman JL. Sequelae of prolonged and repeated trauma. Evidence for a complex posttraumatic syndrome (DESNOS). In: Davidson JR, Foa EB, eds. Post-traumatic stress disorder: DSM-IV and beyond. Washington DC, American Psychiatric Press, 1993.

22. Cardozo BL et al. Mental health, social functioning, and disability in postwar Afghanistan. Journal of the American Medical Association, 2004, 292:575-584.

23. Hollander E, Simeon D, Gorman JM. Anxiety disorders. In: Hales RE, Yudofsky SC, Talbott JA, eds. Textbook of psychiatry. Washington DC, American Psychiatric Press, 1994.

24. Tavallai A et al. [Quality of life in the chemical injured, 15 years after exposure to mustard gas]. Behavioral Sciences Journal, 2007, 1:17-25.

25. Mousavi B, Montazeri A, Soroush MR. [Quality of life in disabled (Janbaz) females with spinal cord injury]. Payesh, 2007, 1:75-81 [in Farsi].

26. Hotopf $M$ et al. Gulf war illness - better, worse, or just the same? A cohort study. BMJ (Clinical Research Ed.), 2003, 327:1370-1373

27. Proctor SP et al. Health-related quality of life in Persian Gulf War Veterans. Military Medicine, 2001, 166:510-519.

28. Dougherty PJ. Transtibial amputees from the Vietnam War. Twenty-eight-year follow-up. Journal of Bone and Joint Surgery. American Volume, 2001, 83-A:383-389. 